FÁBIO F. LIMA

\title{
PROCESSOS CRIATIVOS E METODOLOGIAS DE PROJETOS PARA DESIGN E ARQUITETURA: O EXEMPLO DA BIÔNICA
}

\author{
Fábio F. Lima ${ }^{1}$
}

\begin{abstract}
Resumo: Esse artigo discute o papel das metodologias projetuais inseridas enquanto processos de atividades ampliadoras dos potenciais criativos. Enfatiza-se a importância dessa temática dentro dos exercícios profissionais do designer e do arquiteto, tendo a criatividade como condição indispensável. Além disso, o ensino deve propiciar uma habilidade em conceber idéias alicerçadas em fundamentações reais e em argumentos que satisfaçam uma lógica: a forma deve ser justificada enquanto resultado de um processo. A título de exemplo, o artigo faz uma abordagem acerca da biônica, extraindo particularidades de um modelo biológico escolhido com proveito objetivo nas intenções de projeto.
\end{abstract}

Palavras-chave: Metodologia de projeto, processos criativos, biônica.

Abstract: This article discusses the role of projective methodologies inserted amplifying activities as processes of creative potentials. We emphasize the importance of this theme within the exercise of professional designer and architect, and creativity as a prerequisite. Furthermore, education should provide an ability to conceive ideas grounded in real foundations and on arguments that satisfy a logic: the form must be justified as a result of a lawsuit. For example, the article elaborates on the bionics, extracting features of a biological model chosen goal advantage in the design intent.

Keywords: Design methodology, creative processes, bionics.

O currículo de um curso de graduação é composto por muitas disciplinas e, tanto no design quanto na arquitetura, a prática de projetos é uma importante área capaz de realizar uma síntese entre vários campos de conhecimento estudados em paralelo. Com frequência são realizados exercícios visando situações que exigem raciocínios espaciais por meio de formas tridimensionais e desenhos especulativos de propostas, com o intuito de atender a um determinado objetivo e solucionar um problema. Há um número crescente de autores que procuram estabelecer critérios para as sucessivas etapas dos trabalhos projetuais (MARTINEZ, 2000; KOWALTOWSKI, 2006; MUNARI, 1998; CASTRO OLIVEIRA,

\footnotetext{
${ }^{1}$ Fábio F. Lima é graduado em Arquitetura e Urbanismo pela PUC-Goiás (2000) e mestre em Cultura Visual pela FAV-UFG (2006). É Doutorando em Arquitetura e Urbanismo no PPG - FAU/UNB. É professor assistente do Curso de Arquitetura e Urbanismo da FAV - UFG, com experiência na área de Design, Comunicação Visual e Projeto de Arquitetura. Atua nas áreas de criação de imagens infográficas, videográficas, websites e multimídia.
} 
FÁBIO F. LIMA

2007; HSUAN-AN, 1997; BAXTER, 2000), ainda que em âmbitos relativamente distintos ou em escalas de complexidades diferentes.

Não são raras as vezes onde o aluno se depara com problemas típicos do início de uma atividade projetual: "por onde começo?", “como encontro boas soluções sem muita perda de tempo?", “como adequar ou incorporar determinados aspectos a problemas específicos?" O aluno se vê diante de tantos problemas que não consegue fazer um único risco no papel. Se sente tolhido na criação, cerceado por grande número de questões que o impede de lançar-se numa ação. Faltam-lhe tanto instrumentos capazes de encaminhar suas prospecções, contendo um princípio norteador, quanto um acervo ou repertório que possa lhe sustentar. Por essa razão é que são requeridas determinadas metodologias projetuais contendo qualidades mais dinâmicas e libertadoras da criatividade. É necessário prospectar alternativas capazes de inspirar esse aluno e dar-lhe encorajamento: fazer com que se sinta realmente capaz de encontrar boas soluções.

Nesses momentos que envolvem criação é preciso partir de idéias, estratégias e técnicas em estágios graduais de complexidade. Desse modo, nesse ensaio, a proposta é lidar com atividades ampliadoras dos potenciais criativos em conjunto a uma metodologia inquiridora e experimental das atividades de projeto. As ações se desdobram em etapas ricas, complexas e, que não podem ser abrangidas em todas as suas nuances, mas é sempre necessário trazer novos questionamentos e reflexões sobre as possibilidades do ensino nas atividades de criação. Tomando como referência estudos sobre processos criativos (OSTROWER, 2009), sobre as práticas projetuais (KOWALTOWSKI, 2006; CASTRO OLIVEIRA, 2007; MENEZES, 2007; BAXTER, 2000) e sobre metodologias de abordagem multidisciplinar (MUNARI, 1998; HSUAN-AN, 1997; 2002), procura-se enfatizar a importância dessa temática enquanto exercício de uma profissão que contém a criatividade como condição indispensável.

Daí ser importante incluir os processos de projeto nas discussões de planejamento, adequados aos fatores das realidades das salas de aula; considerando ainda um mercado cada vez mais ansioso por trabalhos inovadores e de qualidade. Por fim, a proposta também se estabelece enquanto crítica aos vários tipos de influência trazidos pelos meios massivos de comunicação, comumente propagadores de modismos e tendências equalizadores de mesmos gostos e padrões; também às técnicas redutoras e equiparadas advindas dos usos dos softwares computacionais (em trabalhos niveladores dos seus usuários pela utilização de ferramentas comuns e condicionamentos a um mesmo tipo específico de fazer). 
FÁBIO F. LIMA

Práxis projetual

A disciplina de projeto exige amadurecimento, sendo que o ensino deve propiciar uma habilidade em conceber idéias alicerçadas em fundamentações reais e em argumentos que satisfaçam uma lógica: a forma deve ser justificada enquanto resultado de um processo. A forma, ainda que numa dada circunstância especulativa, não advém do completo acaso. Ela está sempre condicionada a uma resposta de uso ou utilidade, uma vez que o raciocínio ou os elementos de coerência não são perdidos de vista. Pode até apresentar certa superfície gratuita, mas ao final ela recai num emprego de fins específicos.

O fato de não haver uma única maneira de iniciar um projeto, ou a existência de vários tipos de "partidos" amplia enormemente a questão, não consagrando apenas um tipo de caminho. Desse modo, não existem fórmulas capazes de resolver quaisquer tipos de problemas, mas encaminhamentos adequados dirimidos em etapas pontuais. Mais que uma simples questão de representar, uma metodologia atua como mediadora das soluções, se estabelecendo num contexto onde administra e adequa relações.

Assim, o processo de projeto é um conjunto de ocupações intelectuais organizadas em fases de características e resultados bastante distintos. A prática dessa atividade está situada entre os pólos da invenção e da convenção (CASTRO OLIVEIRA, 2007), cujas relações espaciais sustentam a possibilidade de representar o objeto e de materializá-lo. Nos aspectos da invenção, pode-se afirmar que:

a) nem todo desenho de concepção é fruto de um acervo já existente na memória. $O$ traço contém grande dose de criação, pois nem tudo se encontra acabado ou resolvido (MENEZES, 2007). Por esse motivo, a representação manual é indispensável: ela confere aos raciocínios os seus aspectos materiais e ao se desdobrar posteriormente em outras fontes subseqüentes de interesse;

b) as idéias são arroladas a partir de um problema específico, não flutuações quaisquer (MENEZES, 2007). Determinadas ações vão tomando corpo continuamente nas continuidades das propostas (uma idéia leva a outra e assim sucessivamente);

c) os estímulos captados e reiterados em conjunto às imagens mentais fazem parte de uma percepção ativa. Os estímulos são únicos: captados, selecionados, organizados e interpretados numa natureza diferencial. Os estímulos não são nada mecânicos. O indivíduo participa ativamente das escolhas, operando uma profunda intenção nos seus mais variados aspectos (MENEZES, 2007).

Em relação à convenção: 
FÁBIO F. LIMA

a) as normas procuram uniformizar os desenhos por meio das regras, dos ajustes tomados como acordo, traduzindo-os sob o caráter técnico. Os desenhistas não podem fazer nada aos seus bel-prazeres;

b) presta-se à uma intenção com que se pode planejar, analisar e documentar os trabalhos; condição ainda com que se antevê vários tipos de problemas;

c) procura evitar ambigüidades ou falta de clareza: impede problemas na sua execução.

Dessa forma, considerando essas enumerações, é preciso desenvolver o olhar do aluno para aspectos que tragam soluções diferenciadas, cujas particularidades ainda consigam agregar e valorizar recursos naturais, materiais e técnicas acessíveis, realizáveis de fato. É importante lançar mão de seqüências de atividades capazes de estabelecer relações concretas cujos resultados sejam interessantes.

\section{A natureza como fonte de investigação: biônica ou biomimética}

Tanto MUNARI (1998), quanto HSUAN-AN (1997, 2002) lidam com a criação de produtos baseados em etapas de desenho capazes de fornecer diversos tipos de subsídios. Ambos lidam com a biônica e a intenção desse exercício é realizar uma averiguação da técnica, especulando a proposta feita por eles e estabelecendo outros tipos de detalhamento, num posicionamento crítico cuja intenção é de colaborar com o método. Procura-se estabelecer um diálogo com as operações, sendo investigadas em suas características. Cabe examinar especificamente como são adequadas as relações entre os desenhos, equacionando critérios para as suas etapas.

Alguns dos processos compreendem derivações advindas da Bauhaus e, particularmente dos estudos feitos por Kandinski, encaminhados sob o nome de Método Ternário. Kandinski defendia a idéia de transpor as impressões da natureza na sua realidade íntima mais secreta. Procurava resgatar certa essência do mundo natural e, ao mesmo tempo, tratando-a como fonte inesgotável de pesquisa, pela extensa complexidade com que poderia ser empregada.

A Biônica [de bio(logia) + (eletrô)nica, adaptado do inglês bionics]:

Estuda os sistemas vivos [...] para descobrir processos, técnicas e novos princípios aplicáveis à tecnologia. Examina os princípios, as características e os sistemas com transposição de matéria, com extensão de comandos, com transferência de energia e de informação (MUNARI, 1998: 330). 
FÁBIO F. LIMA

Inicialmente a aplicação dos princípios biológicos se dava particularmente no estudo e design da engenharia de sistemas, especialmente sistemas eletrônicos, mas esse uso se disseminou para várias áreas, particularmente o design, a arquitetura e a engenharia. A biônica ou biomimética estuda uma espécie de "revelação do objeto biológico" usada para proveito específico e cuja proposta possa ser desdobrada na execução de determinado esquema ou plano de projeto. Procura compreender os elementos constituintes, forças interatuantes e demais tensões que devem ser observadas nos modelos constituídos segundo suas próprias leis.

Jack E. Steel define a biônica como "a ciência dos sistemas artificiais que apresentam características comuns aos seres vivos ou cujo funcionamento se baseia em sistemas naturais" (STEEL apud HSUAN-AN, 2002:16). Há um tipo específico de conhecimento com que determinadas "leis naturais" são traçadas, cuja ordem propicia aprender fenômenos aerodinâmicos, térmicos, óticos, estruturais, etc. Nesse sentido, as máquinas imitariam ou aplicariam essas características extraídas desses modelos biológicos - resignando-as em "homomorfo-homométricas" e "homológicas projetivas" (HSUAN-AN, 2002).

A partir das formas naturais ou dos vários tipos de objetos biológicos, busca-se realizar procedimentos dentro de uma sistemática descritiva. A natureza pode simultaneamente apresentar, por meio da sua aparência simples, uma alta complexidade na sua gênese, por uma consonância de características como ordem, harmonia, proporção, etc. Estão de tais formas imbricadas que remetem a um estado de equilíbrio, de conformação perfeita. Agregando os fatores climáticos e as características do solo, enquanto fatores exógenos, há um acúmulo de interferências que resultam nas melhores possibilidades com que a natureza pôde se desenvolver. Em resumo, o princípio elementar é que as formas existentes não são assim gratuitamente, mas empreendem uma resposta mais adequada às interveniências - internas e externas - pelas quais se justificam em função de sua resistência ao meio ou sobrevivência.

Além disso, as formas naturais inspiram um lugar de conforto, remetendo a aspectos espontâneos. Os longos anos de interação com a natureza proporcionaram às pessoas uma visão de intimismo e de agradabilidade. Nesse sentido, nas consecuções dos projetos, essas potencialidades naturais implícitas seriam transpostas para os produtos, em etapas que consideram esses recursos identificados transpostos ainda para uma função utilitária. 
FÁBIO F. LIMA

Seqüência metodológica

Cada um dos autores tem sua própria forma de abordar o processo, em conjunturas variáveis de experiências. MUNARI (1998) inicia o método explicitando o estudo de um ouriço-do-mar, em fotografias e descrições textuais. HSUAN-AN (2002) é mais detalhista pois inclui o exercício como uma atividade específica de um plano de aula, constando problemas, objetivos, materiais e métodos, etc. Examinando esses autores, listamos os procedimentos abaixo, incluindo os detalhes das estapas:

1) Escolher um modelo biológico contendo algum aspecto que se queira explorar ou reconhecer.

Esse aspecto pode também ser relativo ao grau de experiência de quem iniciará o trabalho, pois determinadas qualidades podem ser pouco evidentes, exigindo maior esforço em localizá-las. Para esse caso escolhemos um fruto da monguba (Pachira aquática Aubl). Observe os primeiros registros visuais e seus graus de dificuldade (ver fig.01).

A análise de um fruto, de um inseto, de uma semente, de uma flor, de uma ramificação, do movimento de um animal, da flexibilidade de uma cana de bambu, da resistência da casca de um ovo... são certamente úteis ao conhecimento e podem estimular a criatividade (MUNARI, 1998:330).

2) Realizar registros gráficos detalhados sob a forma de croquis, na intenção de compreender determinadas qualidades relevantes e não simplesmente capturar indiferentemente como numa máquina fotográfica. Realizar anotações ou pequenos textos explicativos quando o desenho se mostrar insuficiente no entendimento de quaisquer detalhes. A ordem se dá na:

[...] observação de tais características com muita atenção e registro gráfico em diversos ângulos e de diversas maneiras; análise em maior profundeza dos fenômenos observados (detalhes interessantes e importantes) e tentativas de traduzi-los em desenhos esquemáticos ou croquis (HSUANAN, 2002:184).

Nesse sentido, os desenhos são dispostos sob a forma de esquemas, onde o mais importante é estabelecer uma apreensão da forma. Que o desenho seja capaz de revelar aspectos que normalmente uma primeira visada ou uma fotografia, por exemplo, não ocorreriam. Esse desenho vai proporcionar ao aluno incorporar mentalmente a configuração desse objeto tridimensional, na medida em que cada detalhe é absorvido na atividade (aqui há um processo de escolha das partes, uma relação ativa da percepção, que capta, seleciona e 
FÁBIO F. LIMA

organiza o que julga mais relevante). Essa manipulação do objeto é bastante significativa porque não somente o tato capta a superfície - interna ou externa - mas o olho a percorre minuciosamente, transferindo essa impressão.



fig. 01. desenhos de observação - monguba (Pachira aquática Aubl). 
FÁBIO F. LIMA

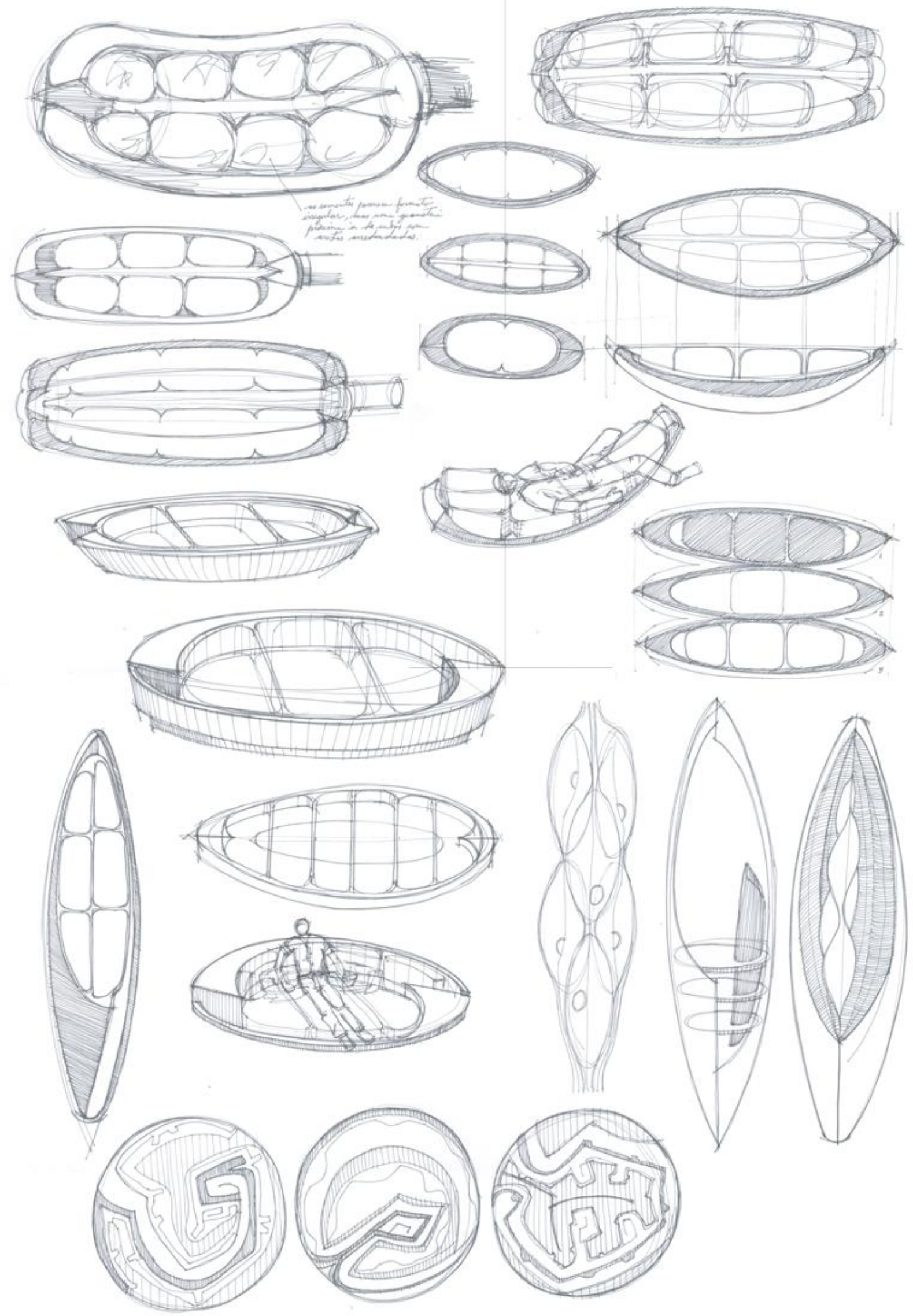

fig.02. desenhos do processo de transformação. 
FÁBIO F. LIMA

3) Transposição gradual das formas para esquemas mais simples, geometrias definidas capazes ainda de resguardar particularidades do modelo (ver fig.02) (redução dos elementos mantendo a conformidade do seu aspecto original, aquilo que conseguiríamos relacionar imediatamente). Em outras palavras:

\footnotetext{
Constrói-se assim um modelo geométrico [...] como se o órgão natural fosse um modelo reconhecível na sua forma e estrutura. A investigação prossegue geometrizando as várias peças, mas conservando suas exatas proporções e funções, continuamente controladas pelo modelo natural (MUNARI, 1998:336).

Construção da abstração geométrica dos detalhes em diversas técnicas de representação bidimensional (em vistas, cortes, perspectivas etc). (HSUANAN, 2002:184).
}

4) conversão para uma possibilidade utilitária (ver fig.02).

Tanto MUNARI quanto HSUAN-AN exploram as questões formais dentro de um conjunto de pesquisa especulativa, mas não tratam dessa característica de uso. Podemos então considerar os desdobramentos tanto possíveis nas aplicações da arquitetura, design ou engenharia.

5) elaborar um modelo para estudos finais: uma maquete que ainda sirva para validação da proposta e testes finais.

Seguindo de forma precisa essas seqüências nos propomos a lidar, como foi dito anteriormente, com o fruto de uma espécie comumente usada na arborização urbana: a monguba, ou Pachira aquática Aubl. Bastante comum nas cidades, seu fruto possui uma aparência simples e, dessa forma, ideal para testar o método. Nas duas páginas seguintes trazemos uma série de desenhos esquemáticos para serem avaliados enquanto parte da metodologia proposta e também detalhada.

\section{Considerações finais}

Procurou-se realizar uma abordagem simples, visando extrair as particularidades do modelo biológico escolhido como proveito objetivo para intenções de projeto. Foram dispostas estratégias de resolução de formatos, estruturas, configurações, etc.

Ainda que nesse exercício tratemos de uma ênfase na captação de aspectos visíveis a olho nu, numa descoberta de aparências manifestadas, existiriam outros vários níveis de complexidade adentrados em escalas distintas, como do nível molecular subcelular ou mesmo os aspectos físico-químicos. Nesse sentido, o exercício limita-se igualmente às questões dessa realidade palpável da sala de aula, dos recursos típicos dos ensinos de graduação. 
FÁBIO F. LIMA

Para além desses aspectos, em meio às tecnologias computacionais, é importante resgatar os valores dos desenhos manuais, onde o aluno possa se reconhecer nos vários estágios, desde os esboços de concepção até o resultado final, algo bastante longe da estandartização promovida pelos computadores, capazes de homogeneizar as coisas sob a perspectiva dos softwares de criação, tratamento e composição de projetos. Cabe uma espécie de crítica às novas tecnologias que trouxeram rapidamente um modo de produção virtual ou imaterial e que se intensifica cada vez mais, tornando-se transparente nos vários usos cotidianos, tão rápida é a assimilação por parte de todos.

Além disso, podemos elucidar o fato que os softwares passam a substituir muitas destrezas manuais. Como processos de adaptação aos instrumentos e materiais, onde as habilidades ficam relegadas a planos secundários. Os computadores estão fortemente ligados a rotinas de produção, comumente conhecidas pelo modo "user friend". Há uma repetição de tarefas mecânicas que nada possuem de criativas. Os processos facilitadores tendem a automatizar as produções. Há um uso bastante limitado das suas funções. A interface amigável traz um remanso tranqüilizador ao usuário, cabendo apenas escolher uma opção das categorias que julga mais conveniente.

No dia-a-dia encontramos soluções que apesar de serem feitas por empresas diferentes, aparentam ser realizadas pelo mesmo designer, usando os mesmo efeitos e processos pirotécnicos dos programas computacionais. Nesse sentido, os usuários passam a ser "funcionários" da máquina, usando suas funções básicas e mínimas. Os computadores se baseiam no poder de repetição e esta pode levar à estereotipia, homogeneidade, previsibilidade, onde teríamos bens materiais e simbólicos comprometidos (MACHADO, 2001).

Desse modo, parece ser fundamental levar às salas-de-aula metodologias que resgatem a importância das experimentações manuais. Construir reflexões para elucidar com maior ênfase algo que passa no interior desses produtos, o que está subentendido por uma grande parte do plano de projeto, aqui necessário desocultar: a importância dos processos de projeto com qualidades libertadoras da criatividade, centradas em processos manuais de desenho. 
FÁBIO F. LIMA

\section{Referências Bibliográficas}

BAXTER, Mike R. Design de Produto: guia prático para o projeto de novos produtos. Trad. Itiro Lida. São Paulo: Edgard Blucher, 2000.

CASTRO OLIVEIRA, Rogério. Teoria e didática do projeto arquitetônico: uma relação permanente. Arquiteturarevista (Unisinos, RS) v.3, n.1,p.57-62, 2007.

HSUAN-AN, Tai. Desenho e organização bi e tridimensional da forma. Goiânia: Ed. da UCG, 1997.

. Sementes do cerrado e design contemporâneo. Goiânia: Ed. da UCG, 2002.

KOWALTOWSKI, Doris C.C.K. et. all. Reflexão sobre metodologias de projeto arquitetônico. Ambiente Construído, Porto Alegre, v.6, n.2, p.07-19, 2006.

MENEZES, Alexandre A. Percepção, memória e criatividade em arquitetura. Cadernos de Arquitetura e Urbanismo, Belo Horizonte, v.14, n.15, 2007.

MACHADO, Arlindo. O quarto iconoclasmo e outros ensaios hereges. Rio de Janeiro: Rios Ambiciosos, 2001.

MARTINEZ, A. Corona. Ensaio sobre o projeto. Trad. Ane Lise Spaltemberg. Brasília: UNB, 2000.

MUNARI, Bruno. Das coisas nascem coisas. Trad. José Manuel de Vasconcelos. São Paulo: Martins Fontes, 1998.

OSTROWER, Fayga. Criatividade e processos de criação. Petrópolis: Vozes, 2009. 